\title{
Properties of Solvent Cast Polycaprolactone Films Containing Pomegranate Seed Oil Stabilized with Nanocellulose ${ }^{\#}$
}

\author{
Ece Söğüit ${ }^{1, a, *}$ \\ ${ }^{I}$ Department of Food Engineering, Faculty of Engineering, Süleyman Demirel University, 32000 Isparta, Turkey
} *Corresponding author

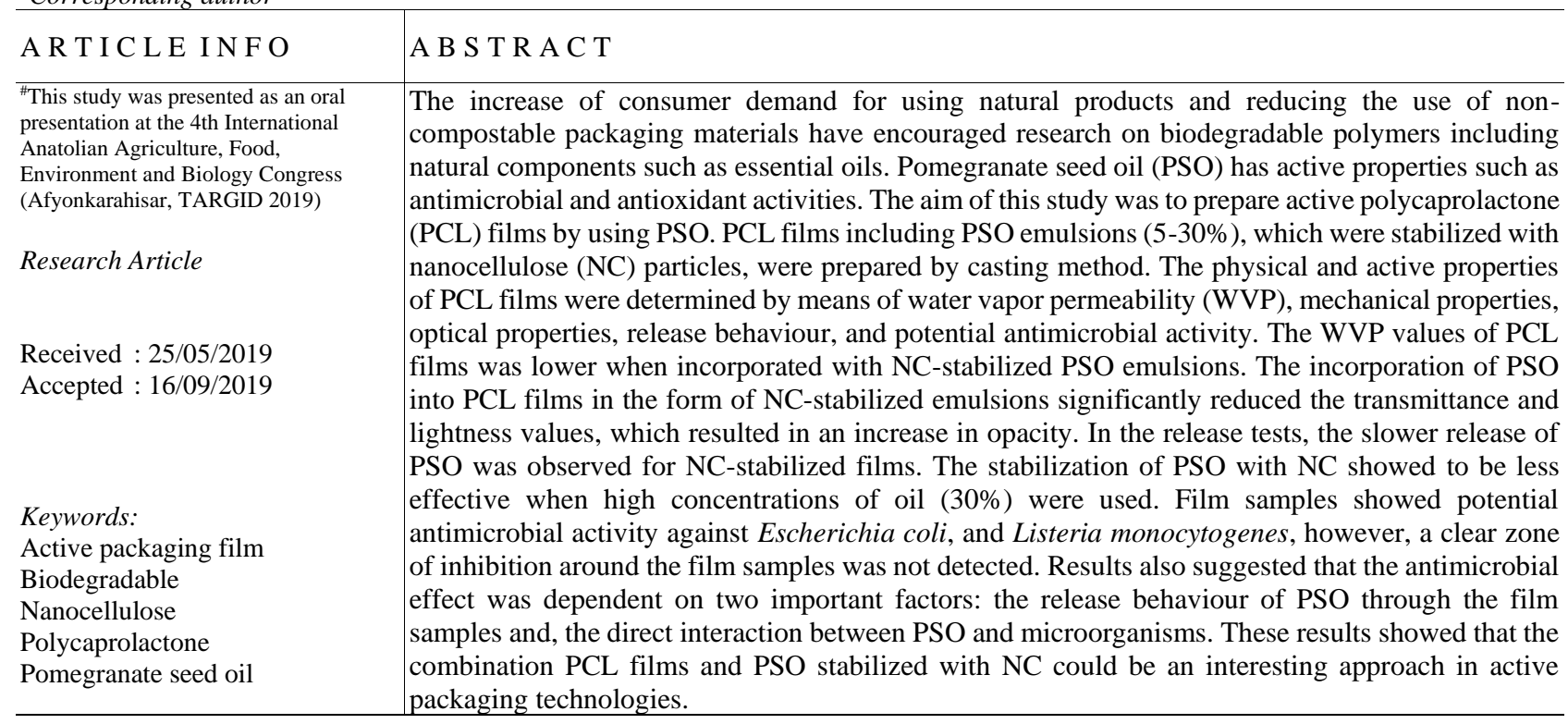

\section{Introduction}

Essential oils are natural volatile compounds, which are formed by aromatic plants as secondary metabolites (Bakkali et al., 2008). These compounds are known for their active properties such as antimicrobial, analgesic, sedative, anti-inflammatory, spasmolytic and antioxidant properties. Among the various natural active agents, pomegranate seed oil (PSO) has gained attention due to its promising properties. PSO is extracted from pomegranate seeds and mainly includes punicic acid with oleic acid, linoleic acid and $\alpha$-eleostearic acid (Kiralan et al., 2009). PSO has been studied for its beneficial effects like antioxidant and antimicrobial properties (Syed et al., 2007; Medjakovic and Jungbauer, 2013; Melo et al., 2014). PSO is a potentially valuable compound for food industry. However, the use of oils alone such as PSO has some drawbacks due to their sensitive structure to light, oxygen, heat and moisture, volatility, having strong odor and weak processability. Besides, the poor solubility of PSO in water limits its use for food applications. To overcome these limitations, PSO can be entrapped with a stabilizing agent into an efficient delivery system such as biodegradable polymers to promote easier handling and appropriate release.

Inorganic particles have been mostly used as stabilizers, but recently it has been shown that nanocellulose (NC) could also stabilize various systems. Different NC types have been stated as a potent stabilizing agent in solid-stabilized emulsions due to the amphiphilic character at the nanocrystals surface (Ougiya et al., 1997). Bacterial cellulose, nanofibrillated cellulose or cellulose nanowhiskers have been successfully used in water emulsions based on peppermint oil (Kasiri and Fathi, 2017), maize germ oil (Zhu et al., 2018), L-ascorbic acid (Khalid et al., 2013). In those mentioned systems, nanosized particles form a rigid structure by adsorbing at the liquid-liquid interfaces and then provide inhibition of droplet coalescence. However, it requires an optimum balance between the solid-liquid and liquid-liquid interfacial tensions, which can be achieved when particles exhibit an amphiphilic character (Sebe et al., 2013). 
In recent years, a tremendous attention has been attracted using bio-based or biodegradable polymers to face the environmental problems arising from excessive use of fossil based polymers (Gross and Kalra, 2002). Polycaprolactone (PCL) is a synthetic biodegradable polymer with its enhanced mechanical and barrier properties (Sharmin et al., 2012). Fabrication of active PCL films by incorporating active agents like PSO is a promising strategy. However, the direct incorporation of PSO into PCL films may result in poor adhesion, incomplete dispersion and phase separation. Therefore, the aim of this study was to combine NC-stabilized PSO with PCL to form an active film suitable for food packaging applications.

\section{Material and Methods}

\section{Materials}

Polycaprolactone (PCL, CAPA 6800) was purchased from Perstorp Holding AB (Sweden). Nanocellulose (NC), which has a crystallinity index of $80 \%$ and crystal length of $100 \mathrm{~nm}$, was supplied by Blue Goose Biorefineries Inc. (BGB ULTRA $^{\mathrm{TM}}$, Canada) in $8.0 \%(\mathrm{w} / \mathrm{w})$ suspension. Ethyl acetate was used as an effective alternate solvent of chloroform, because chloroform is more toxic. Ethyl acetate (anhydrous, 99.8\%) was purchased from SigmaAldrich (St. Louis, Missouri, USA). All other chemicals were analytical grade and purchased from Sigma-Aldrich (St. Louis, Missouri, USA). Pomegranate seed oil (PSO) (including $71.93 \%$ punicic acid) was kindly obtained from the Western Mediterranean Agricultural Research Institute (Antalya, Turkey).

\section{Preparation and Characterization of NC-stabilized PSO}

The NC-stabilized emulsions were prepared using PSO and a $\mathrm{NC}$ aqueous suspension with $50 \mathrm{mM} \mathrm{NaCl}$ at the required concentration. The $\mathrm{NC}$ particle and $\mathrm{PSO}$ ratio is one of the most important parameters on the performance of emulsion. In the preliminary studies, it was observed that the oil droplets started to coalescence when concentrations of NC lower than $0.5 \mathrm{mg} / \mathrm{mL}$ suspension were used. Besides, higher concentrations caused NC to accumulate and to be less effective. Thus, the concentration of $\mathrm{NC}$ in the aqueous suspension containing $50 \mathrm{mM} \mathrm{NaCl}$ was maintained at $2 \mathrm{mg} / \mathrm{ml}$. It was observed that selected $\mathrm{NC}$ concentration is sufficient to cover the interfacial area. The oil/aqueous phase ratio was maintained as 20/80. The mixture of PSO and NC suspension was then homogenized (5000 rpm) for $5 \mathrm{~min}$ (DAIHAN HG-15A, Korea) to prepare the emulsion.

The average diameter $(\mathrm{nm})$, zeta potential $(\mathrm{mV})$, and polydispersity index (pdi) of prepared PSO-nanoemulsion were measured with a nanoparticle analyzer (Horiba Scientifica, Nanopartica, SZ-100V2) to ensure the success of the nanoemulsion production. The PSO included NCbased emulsion was observed by a Carl Zeiss inverted microscope (Primo Vert, Germany) using a digital camera (Primo Vert HDcam, Germany). The image of diluted PSO-nanoemulsion was taken with Labscope 2.0 (Carl Zeiss, Germany) video acquisition software.

Subsequently, the prepared emulsion was freeze-dried (BW-100F, Bluewave Industry Co., Ltd. Shanghai, China) to obtain NC-stabilized PSO.

\section{Film Preparation}

A PCL film solution was obtained by dissolving the PCL in ethyl acetate $(5 \%, \mathrm{w} / \mathrm{w})$. NC-stabilized PSO at 5, 10,20 , and $30 \% \mathrm{w} / \mathrm{w}$ in a dry PCL-based film were then added to the PCL film solution. $50 \mathrm{~g}$ of each film solution was cast onto a Teflon ${ }^{\circledR}$ coated plate $(\varnothing=150 \mathrm{~mm})$ and dried in ambient conditions. All film samples were conditioned at $25^{\circ} \mathrm{C}$ and $50 \% \mathrm{RH}$ for one week before analysis. The thickness of conditioned films was measured at six random positions with a digital micrometer (Digimatic Micrometer Quantu-Mike IP65, Mitutoyo, Japan). PCL films containing NC-stabilized PSO at 5, 10, 20 and $30 \%$ w/w were coded as PCL-5, PCL-10, PCL-20 and PCL-30, respectively.

\section{Optical Properties}

The opacity of film samples was determined by placing $1 \times 4 \mathrm{~cm}$ rectangular film strips into a UV-visible spectrophotometer (Shimadzu, UV-1601, Japan) test cell to take the absorption spectrum of the sample from $400 \mathrm{~nm}$ to $800 \mathrm{~nm}$. The results were measured by the area under the curve divided by the film thickness and expressed in absorbance units (AU nm/mm). The transparency of the films was determined by measuring the percent transmittance at a wavelength of $450 \mathrm{~nm}$ using a UVvisible spectrophotometer (Shimadzu, UV-1601, Japan). The color of the films was measured with a Minolta Chroma Meter (CR-400, Konica Minolta, Inc., Japan) by using a white standard calibration plate $(\mathrm{Y}=92.7$, $\mathrm{x}=0.3160, \mathrm{y}=0.3321$ ) as a background for color measurement of the films. Results were expressed as CIE $L^{*}$ (lightness), $a^{*}$ (red-green) and $b^{*}$ (yellow-blue) coordinates in the color space.

\section{(WVP) \\ Mechanical Properties and Water Vapor Permeability}

The mechanical properties, namely tensile strength (TS) and elongation-at-break (E, \%) were determined by the ASTM standard method D882 (ASTM, 2018). Films were mounted in the film-extension grips of the universal testing machine (Lloyd LR5, AMETEK, Inc, UK) and stretched at $50 \mathrm{~mm} / \mathrm{min}$.

The WVP of films was determined according to the E96/E96M-16 gravimetric method (ASTM, 2016). Film samples were exposed to $100 \% \mathrm{RH}$ and the permeability measurements were performed by weighing the cups periodically (every $1.5 \mathrm{~h}$ for $48 \mathrm{~h}$ ) at $25^{\circ} \mathrm{C}$.

\section{Release Studies}

The release of PSO from the film samples into food simulant D1 (Ethanol 50\% v/v) was tested. $100 \mathrm{mg}$ film sample was immersed in $10 \mathrm{~mL}$ of the simulant in amber glass and continuously stirred throughout the experiment. After various exposure times, the concentration profile of each simulant was determined by absorbance measurements using the corresponding calibration curve. The most abundant active compound in PSO is punicic acid. The Korsmeyer Peppas (Korsmeyer et al., 1983) model was applied to the data to estimate the release kinetics.

$$
M_{t} / M_{\infty}=k t^{n}
$$


Where $M_{t} / M_{\infty}$ is the fraction of active compound released at time $(t), k$ is the rate constant (a characteristic of the matrix related to the diffusion process) and $n$ is the diffusion exponent (characteristic of the release mechanism).

\section{Antimicrobial Activity}

The antimicrobial effects of film samples including PSO were tested against Escherichia coli (ATCC 26922) and Listeria monocytogenes (ATCC 19115) with a zone of inhibition assay on solid media. All microorganisms were incubated at suitable temperatures before the tests and the brain heart infusion (BHI) solid media was inoculated with these cultures (with colony counts from $10^{6}$ to $\left.10^{8} \mathrm{CFU} / \mathrm{mL}\right)$. Film samples $(\varnothing=15 \mathrm{~mm})$ were placed on Petri dishes inoculated with bacterial strains. The plates were incubated at $37^{\circ} \mathrm{C}$ for $24 \mathrm{~h}$ and were then examined for antimicrobial activity.

\section{Statistical Analysis}

An analysis of variance (ANOVA) and Tukey's multiple comparison tests were used to compare the different treatments at a 95\% confidence level. The statistical analysis was performed using Minitab 17 software (Minitab Inc., Brandon, UK). Three observations were performed for each sample and each experiment was replicated three times.

\section{Results and Discussion}

\section{Characterization of Prepared PSO-emulsion}

The images of PSO emulsion were taken with an optical microscopy. As can be seen in Figure 1, PSO was dispersed in $\mathrm{NC}$ aqueous suspension in $50 \mathrm{mM} \mathrm{NaCl}$ without aggregation. This behavior might be due to that $\mathrm{NC}$ particles effectively adsorbed at the interface, resulting in a resistance against coalescence (Kalashnikova et al.,
2012). The average diameter ( $\mathrm{nm})$, zeta potential $(\mathrm{mV})$, and polydispersity index (pdi) of prepared PSO-emulsion were found as $151.3 \pm 14.6,-37.9 \pm 5.1$, and $0.6 \pm 0.1$, respectively. The zeta potential lower than $-30 \mathrm{mV}$ and higher than $30 \mathrm{mV}$ are indication of stable systems to be sufficient for ensuring physical stability of nanoemulsion (Gurpreet and Singh, 2018). The zeta potential of prepared emulsion is within acceptable limits $( \pm 30 \mathrm{mV})$, which can be accepted as stable emulsion. The average diameter and pdi were used to understand the success of the nanoemulsion production. Typical nanoemulsions present pdi values between 0.3 and 0.5 and higher pdi values than 0.3 are indication of destabilized emulsions (Zdrali et al., 2019). The average diameter of prepared emulsion is between $20-200 \mathrm{~nm}$ that can be accepted as nanoemulsion (Gurpreet \& Singh, 2018).

\section{Optical Properties}

Table 1 shows the optical properties of film samples. Visually, oil droplets were not detected on the surface of film samples by the help of high resistance to coalescence for the film solution including NC stabilized PSO. PCL films showed $30.07 \%$ transmittance whereas PSO including films presented significantly lower transmittance due to the existing of NC-stabilized oil layer, which could be used as an effective light barrier. These types of films could meet the requirements needed to prevent food products from oxidation induced by light. In general, the increasing amount of PSO resulted in lower transmittance and higher opacity values $(\mathrm{P}<0.05)$, which might be due to the impenetrable matrix created by oil droplets promoting light scattering throughout the film (Tongnuanchan et al., 2013). PCL films showed the highest $L^{*}$ values consistent with the transparency values $(\mathrm{P}<0.05)$. The $L^{*}$ values did not change significantly, however, the $a^{*}$ and $b^{*}$ values were found significantly higher than those of PCL films $(\mathrm{P}<0.05)$.
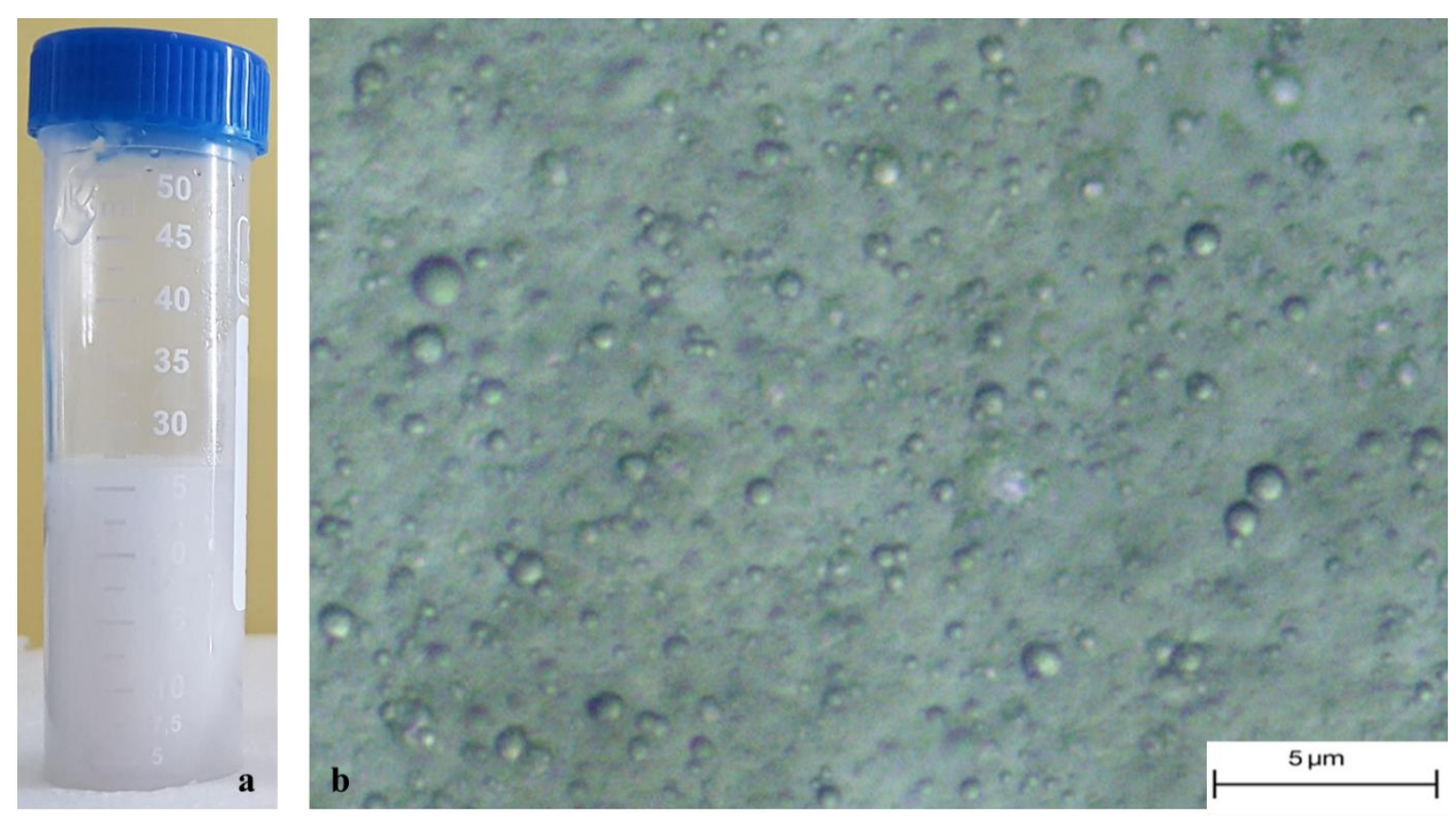

Figure 1 The image (a) and optical micrograph of prepared PSO-emulsion (b) 
Table 1 Optical properties

\begin{tabular}{l|rrrrr}
\hline Film sample & $\begin{array}{c}\text { Opacity }(\mathrm{AU} \\
\mathrm{nm} / \mathrm{mm}) \times 10^{3}\end{array}$ & \multicolumn{1}{c}{$\mathrm{T}(\%)$} & $L^{*}$ & $a^{*}$ & $b^{*}$ \\
\hline PCL & $1.76 \pm 0.04^{\mathrm{c}}$ & $30.07 \pm 0.12^{\mathrm{a}}$ & $97.28 \pm 0.09^{\mathrm{a}}$ & $-0.13 \pm 0.03^{\mathrm{a}}$ & $2.13 \pm 0.02^{\mathrm{d}}$ \\
PCL-5 & $2.71 \pm 0.15^{\mathrm{b}}$ & $3.93 \pm 0.50^{\mathrm{b}}$ & $96.52 \pm 0.07^{\mathrm{c}}$ & $-0.48 \pm 0.01^{\mathrm{c}}$ & $3.60 \pm 0.15^{\mathrm{a}}$ \\
PCL-10 & $3.40 \pm 0.29^{\mathrm{ab}}$ & $3.63 \pm 0.35^{\mathrm{b}}$ & $96.60 \pm 0.04^{\mathrm{bc}}$ & $-0.46 \pm 0.04^{\mathrm{c}}$ & $3.30 \pm 0.12^{\mathrm{b}}$ \\
PCL-20 & $3.26 \pm 0.15^{\mathrm{ab}}$ & $2.53 \pm 0.46^{\mathrm{b}}$ & $96.91 \pm 0.06^{\mathrm{b}}$ & $-0.37 \pm 0.01^{\mathrm{b}}$ & $2.87 \pm 0.10^{\mathrm{c}}$ \\
PCL-30 & $3.92 \pm 0.35^{\mathrm{a}}$ & $2.40 \pm 0.26^{\mathrm{b}}$ & $96.84 \pm 0.24^{\mathrm{bc}}$ & $-0.36 \pm 0.05^{\mathrm{b}}$ & $2.85 \pm 0.07^{\mathrm{c}}$ \\
\hline
\end{tabular}

${ }^{\mathrm{a}-\mathrm{d}}$ Means in the same column with different superscripts differ significantly $(\mathrm{P}<0.05)$ according to Tukey test

Table 2 Mechanical properties and water vapor permeability values

\begin{tabular}{l|cccc}
\hline Film sample & Thickness (mm) & $\begin{array}{c}\text { WVP } \\
\left(10^{-6} \mathrm{gh}^{-1} \mathrm{~m}^{-1} \mathrm{~Pa}^{-1}\right)\end{array}$ & TS (MPa) & E $(\%)$ \\
\hline PCL & $0.11 \pm 0.01^{\mathrm{b}}$ & $0.95 \pm 0.68^{\mathrm{b}}$ & $*$ & $*$ \\
PCL-5 & $0.16 \pm 0.02^{\mathrm{ab}}$ & $3.10 \pm 0.62^{\mathrm{a}}$ & $*$ & $31 \pm 2^{\mathrm{a}}$ \\
PCL-10 & $0.19 \pm 0.02^{\mathrm{a}}$ & $3.16 \pm 0.78^{\mathrm{a}}$ & $18 \pm 3^{\mathrm{b}}$ & $40 \pm 1^{\mathrm{a}}$ \\
PCL-20 & $0.19 \pm 0.01^{\mathrm{a}}$ & $1.59 \pm 0.33^{\mathrm{ab}}$ & $17 \pm 2^{\mathrm{b}}$ & $68 \pm 2^{\mathrm{a}}$ \\
PCL-30 & $0.20 \pm 0.04^{\mathrm{a}}$ & $2.35 \pm 0.85^{\mathrm{a}}$ & $6 \pm 1^{\mathrm{b}}$ \\
\hline
\end{tabular}

*PCL and PCL-5 films did not break at determined conditions

${ }^{a-b}$ Means in the same column with different superscripts differ significantly $(\mathrm{p}<0.05)$ according to Tukey test.

Table 3 Korsmeyer-Peppas model parameters

\begin{tabular}{l|ccc}
\hline Film sample & $n$ & $k$ & $\mathrm{R}^{2}$ \\
\hline PCL-5 & $0.2035^{\mathrm{c}}$ & $0.8934^{\mathrm{b}}$ & 0.89 \\
PCL-10 & $0.2376^{\mathrm{b}}$ & $0.7644^{\mathrm{c}}$ & 0.87 \\
PCL-20 & $0.3066^{\mathrm{a}}$ & $0.7688^{\mathrm{c}}$ & 0.78 \\
PCL-30 & $0.2412^{\mathrm{b}}$ & $1.0194^{\mathrm{a}}$ & 0.88 \\
\hline
\end{tabular}

${ }^{\mathrm{acc}}$ Means in the same column with different superscripts differ significantly $(\mathrm{P}<0.05)$ according to Tukey test

\section{Mechanical Properties and Water Vapor Permeability (WVP)}

Table 2 shows the mechanical properties and WVP values of film samples. The thickness of films increased when NC stabilized PSO was added to PCL films, whereas the thickness of PCL-30 films were the highest $(\mathrm{P}<0.05)$. The differences in the thickness of the film samples can be related to the interactions between PCL and other ingredients inside the film matrix (Talon et al., 2017).

The tensile strength (TS) of film samples decreased with the increase in PSO content $(\mathrm{P}<0.05)$. PCL-10 films exhibited the highest TS values while high oil fraction made films fragile. This behavior can be explained by the interfacial interactions between stabilized oil droplets and polymer matrix. Similarly, Zhu et al. (2018) reported that the high oil concentration resulted in more fragile films. The addition of higher PSO to the film samples tended to increase the chain mobility and decrease the TS. The decrease in TS at higher PSO levels than $20 \%$ might be also associated with an incompatibility between polymer and NC stabilized PSO. Besides, up to $20 \%$ PSO content the elongation of PCL films significantly increased and above $20 \%$ of PSO, it tended to decrease $(\mathrm{P}<0.05)$. These results are in agreement with Chen et al. (2016) who studied chitosan films including cinnamaldehyde-loaded nanoemulsions.

PCL films showed the lowest WVP values, and the increase in PSO content caused a decrease in water barrier resistance. The addition of a more hydrophobic compound did not result in a strong decrease in WVP. Similarly, it was reported that the addition of thymol nanoemulsions to protein/chitosan films (Robledo et al., 2018) and the addition of carvacrol and cinnamaldehyde nanoemulsions (Otoni et al., 2016) to soy protein increased the overall permeability.

\section{Release Studies}

The Korsmeyer-Peppas model parameters for PSO release in D1 simulant are shown in Table 3. For thin films, the $n$ values equal to 0.5 is explained by Fickian diffusion and $n$ equals to 1.0 is explained by relaxational transport, whereas anomalous transport behavior is defined by $n$ values between 0.5 and 1.0 (Siepmann and Peppas, 2011). All film samples had lower $n$ values than 0.5 resulted in non-Fickian behavior. These small values of $n$ might be attributed to the partial film solubility in D1 simulant. The highest $k$ value was observed in PCL-30 films and there was no significant difference between other film samples for $k$ values.

The release behavior of PSO from film samples as a function of time is shown in Figure 2. The release of an agent from a polymeric matrix occurs firstly with the diffusion of solvent through the polymer matrix followed by the relaxation and then finally finished by the diffusion of agent through the polymer matrix (Tampau et al., 2018). The increase in PSO content resulted in faster release. The interaction between PCL and 5\% of NC stabilized PSO might be favored thus leading a slower release of PSO with a more close structure. 


\section{Antimicrobial Activity}

The agar diffusion method was performed to evaluate the inhibition capacity based on the clear zone surrounding the hole. The PCL films without NC-stabilized PSO were chosen as control and there was also a microbial growth under PCL films in solid media. Even though there was no growth with PSO-added film samples in the solid media inoculated with microorganisms, films did not show a clear zone. Since there was no microbial growth under PCL films including NC-stabilized PSO, it was considered that these films had a potential antimicrobial activity. This behavior can be explained by the decreased accessibility of NC-stabilized PSO compounds due to the effectiveness of $\mathrm{NC}$ adsorption at the oil interface. The strong interaction between PSO and NC inside PCL matrix might also prevent PSO from rapid release into solid media (Froiio et al., 2019). Recently, Xylia et al. (2017) reported that pomegranate seed extracts and oils had the potential to inhibit various microorganisms. Other researchers who have studied PCL films including different antimicrobial agents like pine resin (Chang et al., 2019), Thymus capitatus and Origanum vulgare essential oils (Granata et al., 2018) and pomegranate rind (Khalid et al., 2018) reported that the minimum inhibitory concentration of active agents was greater than the acceptable levels included in the films. The authors also stated that the effectiveness of antimicrobial activity of the film samples was strongly related to the retention and diffusivity mechanism of active compounds in the matrix.

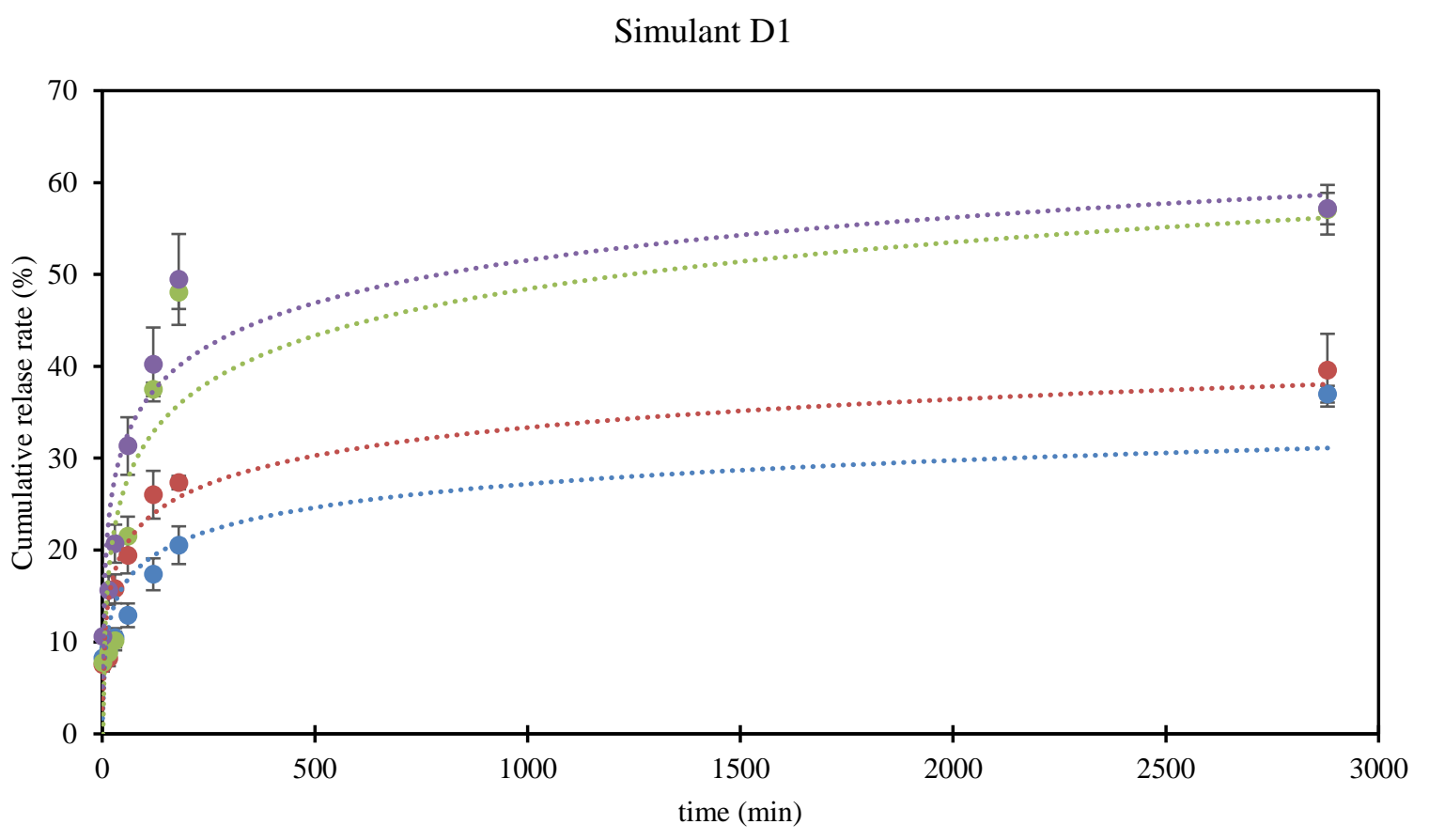

- PCL-5 PPCL-10 PCL-20 P PCL-30

Figure 2 Cumulative release of PSO from film samples

\section{Conclusion}

In this study, the active PCL films were prepared by using PSO emulsions (5-30\%), which were stabilized with NC particles. The barrier properties against water and the tensile strength of films including NC-stabilized PSO slightly decreased however, the release of PSO from films showed slower rates when stabilized with NC. The incorporation of PSO into PCL films in the form of NCstabilized emulsions reduced the transmittance and lightness values whereas film samples showed a potential antimicrobial activity against Escherichia coli and Listeria monocytogenes. The stabilization of PSO with NC showed to be less effective when high concentrations of oil (30\%) were used. These results suggest that the combination of PCL films and PSO stabilized with NC could be an interesting approach in active packaging technologies.

\section{References}

ASTM. 2016. Standard test methods for water vapor transmission of materials: E96/E96M-16. In Annual book of American Society for Testing and Materials Standards (Vol. 04.06, pp. 14). West Conshohocken, PA: ASTM.

ASTM. 2018. Standard test method for tensile properties of thin plastic sheeting: D882. In Annual book of American Society for Testing and Materials standards (Vol. 08.01, pp. 12). West Conshohocken, PA: ASTM.

Bakkali F, Averbeck S, Averbeck D, Idaomar M. 2008. Biological effects of essential oils - A review. Food and Chem Toxicol., 46(2): 446-475.

Caio G, Otoni CG, Avena-Bustillos RJ, Olsen CW, Bilbao-Sáinz C, McHugh TH. 2016. Mechanical and water barrier properties of isolated soy protein composite edible films as affected by carvacrol and cinnamaldehyde micro and nanoemulsions. Food Hydrocolloid., 57: 72-79. 
Chang R, Rohindra D, Lata R, Kuboyama K, Ougizawa T. 2019. Development of poly(epsilon-caprolactone)/pine resin blends: Study of thermal, mechanical, and antimicrobial properties. Polym Eng Sci., 59: E32-E41

Chen H, Hu X, Chen E, Wu S, Mc Clements DJ, Liu S, Li B, Li Y. 2016. Preparation, characterization, and properties of chitosan films with cinnamaldehyde nanoemulsions. Food Hydrocolloid., 61:662-671.

Froiio F, Ginot L, Paolino D, Lebaz N, Bentaher A, Fessi H, Elaissari A. 2019. Essential Oils-Loaded Polymer Particles: Preparation, Characterization and Antimicrobial Property. Polym., 11:1017.

Granata G, Stracquadanio S, Leonardi M, Napoli E, Consoli GML, Cafiso V, Stefani S, Geraci C. 2018. Essential oils encapsulated in polymer-based nanocapsules as potential candidates for application in food preservation. Food Chem., 269: 286-292.

Gross RA, Kalra B. 2002. Biodegradable polymers for the environment. Science., 297:803-807.

Gurpreet K, Singh SK. 2018. Review of Nanoemulsion Formulation and Characterization Techniques. Indian $\mathrm{J}$ Pharm Sci., 80(5):781-789.

Kalashnikova I, Bizot H, Bertoncini P, Cathala B, Capron I. 2012. Cellulosic nanorods of various aspect ratios for oil in water Pickering emulsions. Soft Matter, 9(3):952-959.

Kasiri N, Fathi M. 2017. Entrapment of peppermint oil using cellulose nanocrystals. Cellulose., 1:1-11

Khalid N, Kobayashi I, Neves MA, Uemura K, Nakajima M. 2013. Preparation and Characterization of Water-in-Oil-inWater Emulsions Containing a High Concentration of LAscorbic Acid. Biosci Biotech Bioch., 77(6):1171-1178

Khalid S, Yu L, Feng MY, Meng LH, Bai YT, Ali A, Liu HS, Chen L. 2018. Development and characterization of biodegradable antimicrobial packaging films based on polycaprolactone, starch and pomegranate rind hybrids. Food Packaging Shelf., 18:71-79.

Kiralan M, Gölükcü M, Tokgöz H. 2009. Oil and Conjugated Linolenic Acid Contents of Seeds from Important Pomegranate Cultivars (Punica granatum L.) Grown in Turkey. J Am Oil Chem Soc., 86(10):985-990.

Korsmeyer RW, Gurny R, Doelker E, Buri P, Peppas NA. 1983. Mechanisms of solute release from porous hydrophilic polymers. Int J Pharm., 15(1):25-35.
Medjakovic S, Jungbauer A. 2013. Pomegranate: a fruit that ameliorates metabolic syndrome. Food Funct. 4(1):19-39.

Melo ILP, Carvalho EBT, Mancini-Filho J. 2014. Pomegranate seed oil (Punica Granatum L.): A source of punicic acid (conjugated $\alpha$-linolenic acid). J Hum Nutr Diet., 2(1):1024.

Ougiya H, Watanabe K, Morinaga Y, Yoshinaga F. 1997. Emulsion-stabilizing Effect of Bacterial Cellulose. Biosci Biotechnol Biochem., 61:1541-1545.

Robledo N, Vera P, López L, Yazdani-Pedram M, Tapia C, Abugoch L. 2018. Thymol nanoemulsions incorporated in quinoa protein/chitosan edible films; antifungal effect in cherry tomatoes. Food Chem., 246: 211-219

Sebe G, Ham-Pichavant F, Pecastaings G. 2013. Dispersibility and Emulsion-Stabilizing Effect of Cellulose Nanowhiskers Esterified by Vinyl Acetate and Vinyl Cinnamate. Biomacromolecules., 14(8): 2937-2944.

Sharmi, N, Khan RA, Salmieri S, Dussault D, Lacroix M. 2012. Fabrication and Characterization of Biodegradable Composite Films Made of Using Poly(caprolactone) Reinforced with Chitosan. J Polym Environ., 20(3):698-705.

Siepmann J, Peppas NA. 2011. Higuchi equation: Derivation, applications, use and misuse. Int J Pharm., 418(1):6-12.

Syed, DN, Afaq F, Mukhtar H. 2007. Pomegranate derived products for cancer chemoprevention. Semin Cancer Biol., 17(5):377-385.

Talón E, Trifkovic KT, Vargas M, Chiralt A, González-Martínez C. 2017. Release of polyphenols from starch-chitosan based films containing thyme extract. Carbohyd Polym., 175:122130.

Tampau A, González-Martínez C, Chiralt A. 2018. Release kinetics and antimicrobial properties of carvacrol encapsulated in electrospun poly-(e-caprolactone) nanofibres. Application in starch multilayer films. Food Hydrocolloid., 79:158-169.

Tongnuanchan P, Benjakul S, Prodpran T. 2013. Physicochemical properties, morphology and antioxidant activity of film from fish skin gelatin incorporated with root essential oils. J Food Eng., 117(3):350-360.

Zdrali E, Okur HI, Roke S. 2019. Specific ion effects at the interface of nanometer-sized droplets in water: structure and stability. J Phys Chem C., 123:16621-16630.

Zhu XY, Tang CH, Yin SW, Yang XQ. 2018. Development and characterization of novel antimicrobial bilayer films based on Polylactic acid (PLA)/Pickering emulsions. Carbohyd Polym., 181: 727-735. 